\title{
Discussion: Flow nets and textbooks
}

\section{E. Bromhead}

\section{A. N. Beal, Thomasons LLP, UK}

There is an error of the same kind in Figure 9 in the current BS Code of Practice for Earth Retaining Structures, BS 8002. ${ }^{28}$ This shows a simplified method for estimating variation of hydraulic head on a retaining wall which has water on both sides. Figure 9 is not strictly a flow net, but it is closely related-and it contains two obvious errors: (a) on the lower side of the wall, water pressure is shown being applied to the wall above the water table, which is impossible; and (b) although the text says that the variation should be considered as linear along the seepage path, the diagram shows the maximum head at the bottom of the wall, even though the path lengths on the two sides of the wall are completely different.

\section{Author's reply}

The author is grateful to Mr Beal for highlighting a significant issue, and is relieved to find that he is not alone in being concerned at the way in which pore water pressures are often mishandled.

The review in the paper needed to be given bounds, and those were simply the books in the author's own collection, supplemented by a few held by a colleague at Kingston University. Some are best described as 'museum pieces'. The list is not exhaustive, and indeed, after writing the paper, some more volumes came to light. They too contained errors in the flow nets!

The intention was not to single out a particular book and its author(s) for criticism over a single mistake, but to highlight how mistakes have been carried over from edition to editionin some cases through seven editions-without rectification. Perhaps more worrying to the author of the paper in his role as a teacher is that the subject is not well covered with textbook examples, that the same examples have been used over decades between books, and that, in the process, they have carried across the same mistakes not simply from edition to edition, but from book to book and from author to author.

\section{REFERENCE}

28. BRITISH StANDARDS InSTITUTION. Code of Practice of Earth Retaining Structures. BSI, London, 1994, BS 8002. 